\title{
De rol van het Digitaal Kenniscentrum Seksespecifiek Medisch Onderwijs bij de integratie van sekse in het medisch onderwijs
}

\author{
L.J.L. Mans, P. Verdonk, A.L.M. Lagro-Janssen
}

\section{Samenvatting}

Inleiding: Uit de evaluatie van het Nijmeegse pilotproject 'Integratie van sekse in het medisch basiscurriculum' bleek dat het aanbieden van concreet onderwijsmateriaal met relevantie voor de dagelijkse medische praktijk van groot belang is bij het succesvol implementeren. Een Digitaal Kenniscentrum Seksespecifiek Medisch Onderwijs (DKSMO) is als instrument gebruikt om tijdens het landelijke project aan alle medische faculteiten seksespecifiek medisch onderwijsmateriaal beschikbaar te stellen. Doel van dit onderzoek is te kijken hoe de gebruikers het DKSMO beoordelen en of het een faciliterende rol speelt bij de integratie van sekse in het medisch onderwijs.

Methode: Uit het bestand van 100 personen die zich vóór juli 2004 hebben aangemeld om toegang te krijgen tot het onderwijsmateriaal en die concreet als docent werkzaam zijn op de verschillende medische faculteiten, zijn twintig docenten en blokcoördinatoren geselecteerd. Zij kregen een enquête toegestuurd. Tot de onderzoeksgroep behoorden zeventien respondenten van zes faculteiten.

Resultaten: Zes van de zeventien respondenten hebben het onderwijsmateriaal uit het $D K S M O$ in hun onderwijs gebruikt en vonden het materiaal handzaam en gemakkelijk in te bouwen. Redenen om het onderwijsmateriaal niet te gebruiken zijn: het verkrijgen van papieren onderwijsmateriaal op maat, geen onderwijsmateriaal aanwezig (in de gewenste vorm), vertraging in het systeem van het DKSMO en het nog niet bezig zijn met concreet onderwijs maken. Wel fungeerde het onderwijsmateriaal als voorbeeld om zelf opdrachten te maken.

Conclusie: Het DKSMO speelt een faciliterende rol bij de integratie van sekse in het medisch basiscurriculum. Het gebruik bevordert de implementatie en internet maakt het seksespecifiek onderwijsmateriaal toegankelijk. Ondersteuning op maat door genderdeskundigen echter is noodzakelijk. (Mans LJL, Verdonk P, Lagro-Janssen ALM. De rol van het Digitaal Kenniscentrum Seksespecifiek Medisch Onderwijs bij de integratie van sekse in het medisch onderwijs. Tijdschrift voor Medisch Onderwijs 2006;25(2):66-74.)

\section{Inleiding}

Een landelijk project met als doel om te komen tot seksespecifieke medische curricula in minimaal zes van de acht medische faculteiten ging in opdracht van het Ministerie van Volksgezondheid, Welzijn en Sport van start in april 2002. In het algemeen spreekt men van seksespecifiek medisch onderwijs indien studenten inzicht verwerven in de betekenis van sekse voor gezondheid en ziekte en dit adequaat leren toe te passen in de medische praktijk. ${ }^{1-4}$ Voor dit project werden aan de hand van literatuur en internationale projecten specifieke criteria geformuleerd, waaraan een geslaagde integratie van sekse in een medisch curriculum moet voldoen. ${ }^{2}$ Het proces van implementatie van sekse vereist een multidisciplinaire aanpak in gebruikte strategieën. ${ }^{5-6}$ Uit de evaluatie van een Nijmeegs pilotproject bleken verschillende aspecten van groot 
belang bij het succesvol implementeren: de noodzakelijke financiële middelen, ondersteuning op beleidsniveau, ondersteuning door een trekker en het aanbieden van concreet onderwijsmateriaal met relevantie voor de dagelijkse medische praktijk. ${ }^{2}$ Aan belemmeringen zoals gebrek aan tijd wordt daarmee tegemoet gekomen. Ook gebrek aan expertise in de faculteiten om medisch onderwijs seksespecifiek te maken is een belemmering voor de integratie van sekse. ${ }^{5}$ Daarom is direct bij aanvang van het project een Kenniscentrum Seksespecifiek Medisch Onderwijs ingericht. Docenten kunnen seksespecifiek medisch onderwijsmateriaal verkrijgen via het kenniscentrum en de projectmedewerkers bieden ondersteuning op maat voor de implementatie van de factor sekse in het medisch onderwijs. Ondersteuning op maat houdt bijvoorbeeld in dat de projectmedewerkers blokboeken screenen en de aanbevelingen voor integratie van seksespecifieke onderwerpen bespreken met de betreffende blokcoördinatoren. Het kenniscentrum functioneert tevens als centrum voor inventarisatie en documentatie.

De website van het Kenniscentrum Seksespecifiek Medisch Onderwijs, het Digitaal Kenniscentrum Seksespecifiek Medisch Onderwijs (DKSMO), is een instrument om seksespecifiek medisch onderwijsmateriaal beschikbaar te stellen voor docenten uit het medisch onderwijs. Overduin en Meerdink noemen verschillende functies die van toepassing zijn op dit project. ${ }^{7}$ Ten eerste vergroot de website de toegankelijkheid tot het seksespecifiek onderwijsmateriaal en versnelt deze de beschikbaarheid. Bovendien informeert de website bezoekers over seksespecifieke geneeskunde en over het doel van het project 'De integratie van sekse in het medisch basiscurriculum'. De website heeft daarmee een belangrijke richtinggevende en motiverende functie.
Het DKSMO bestaat uit een publieke website (www.vrouwenstudiesgeneeskunde.nl) die toegang biedt tot Blackboard, het programma dat de digitale leeromgeving van de Radboud Universiteit Nijmegen en andere universiteiten regelt. In Blackboard is het verzamelde onderwijs ingevoerd onder de 'course' 'Vrouwenstudies geneeskunde'. 8 De projectgroep kon als vanzelfsprekend in Nijmegen aansluiten bij Blackboard en het systeem is goed bekend bij docenten. Bovendien biedt de digitale leeromgeving door het aanmeldingssysteem een beveiliging van het onderwijsmateriaal en was het mogelijk om zicht te krijgen op wie het onderwijsmateriaal gebruikt. Ook speelde een kostenoverweging een rol: door aan te sluiten bij Blackboard hoefde de projectgroep geen eigen database te bouwen.

Het materiaal bestaat uit verschillende onderwijsvormen zoals zelfstudieopdrachten, hoorcolleges (powerpointpresentaties), casuïstiek, (beschrijvingen van) audiovisueel materiaal, achtergrondliteratuur en toetsvragen. Het onderwijsmateriaal is alfabetisch geordend aan de hand van trefwoorden als 'adolescentie', 'communicatie', 'depressie', 'farmacologie', 'seksualiteit' en 'zwangerschap'.

Docenten en beleidsmakers van de verschillende faculteiten kunnen zich via de publieke website aanmelden voor een account om toegang te krijgen tot het seksespecifiek onderwijsmateriaal. Via Blackboard kunnen zij vervolgens het onderwijsmateriaal inzien of overnemen. Daarnaast kunnen zij gericht onderwijsmateriaal opvragen bij de projectmedewerkers.

In dit artikel staat het gebruik van het DKSMO centraal. Daartoe formuleerden wij de volgende vraagstellingen:

1. Hoeveel docenten van de medische faculteiten hebben gebruik gemaakt van het onderwijsmateriaal uit het DKSMO? 
2. Hoe beoordelen de gebruikers het DKSMO en speelt het DKSMO een faciliterende rol bij de integratie van sekse in het medisch onderwijs?

\section{Methode}

Het aantal personen dat zich via de publieke website heeft aangemeld voor toegang tot Blackboard is vanaf de lancering op 1 mei 2003 tot 1 maart 2005 bijgehouden door de beheerders van het DKSMO. Naast aantallen werden ook achtergrondgegevens zoals naam, functie en faculteit/instelling geregistreerd. De 'course statistics' in Blackboard laten zien hoeveel personen het seksespecifiek onderwijsmateriaal hebben bekeken. Uit het bestand van 100 personen die zich vóór 1 juli 2004 hebben aangemeld om toegang te krijgen tot het onderwijsmateriaal zijn 20 personen geselecteerd (tabel 1). Criteria waren dat zij concreet als docent en/of blokcoördinator werkzaam zijn en dat alle medische faculteiten (behalve Nijmegen) geïncludeerd werden. Zij kregen een enquête toegestuurd (bijlage 1). Van de 20 verstuurde enquêtes hebben 17 personen de vragen beantwoord. 10 respondenten retourneerden de enquête; met 7 respondenten zijn telefonische interviews gehouden, waarvan een gespreksverslag is gemaakt. De vragen van de telefonische interviews waren identiek aan die van de enquête. Om een globaal overzicht te krijgen van wat de gebruikers van het DKSMO vinden, hebben we gekozen voor een enquête. Bovendien dienden de interviews om extra inzicht te krijgen in de beoordeling van het DKSMO. De respondenten werd gevraagd hun antwoorden (schriftelijk of mondeling) zo uitvoerig mogelijk toe te lichten. Ter onderbouwing van de resultaten zijn, waar relevant, citaten uit de antwoorden overgenomen.

De respondenten betreffen 6 mannen en 11 vrouwen van 6 verschillende faculteiten (UMC Utrecht uitgezonderd). 3 personen hebben niet gereageerd of gaven aan dat ze geen tijd hadden om de vragen te beantwoorden. 2 van hen waren verbonden aan het UMC Utrecht, waardoor deze faculteit niet tot de onderzoeksgroep behoort. Do-

Tabel 1 Overzicht aanmeldingen Digitaal Kenniscentrum Seksespecifiek Medisch Onderwijs tot 1 juli 2004.

\begin{tabular}{lcc}
\hline Gebruikers & Totaal $(\mathrm{n}=\mathbf{1 0 0})$ & Steekproef $(\mathrm{n}=\mathbf{2 0})$ \\
\hline Geslacht & & \\
Vrouw & 68 & 13 \\
Man & 32 & 7 \\
Medische Faculteiten* & & \\
AMC & 17 & 5 \\
Erasmus MC & 4 & 2 \\
LUMC & 7 & 3 \\
UMC Groningen & 8 & 4 \\
UMC Utrecht & 4 & $2^{+}$ \\
UM/FdG & 5 & 2 \\
VUmC & 6 & 2 \\
Overige instellingen & 49 & - \\
\hline * Het UMC St Radboud is buiten beschouwing gelaten. & \\
\# Inclusief 1 non-responder. & & \\
+ Inclusief 2 non-responders. &
\end{tabular}


centen en blokcoördinatoren van het UMC St Radboud zijn bij deze evaluatie buiten beschouwing gelaten, omdat zij reeds van aanbevelingen en literatuursuggesties voor de integratie van sekse in het onderwijs zijn voorzien tijdens de pilotstudie in $1998^{9}$ en de evaluatie van de pilotstudie in $2002 .^{2}$

\section{Resultaten}

\section{Aantal gebruikers Digitaal Kennis- centrum Seksespecifiek Medisch Onderwijs}

Tussen 1 mei 2003 en 1 maart 2005 zijn 138 personen met een eigen account toegelaten tot het seksespecifiek onderwijsmateriaal in Blackboard; van hen zijn 93 personen werkzaam aan één van de acht medische faculteiten. 45 personen zijn aan andere gezondheidszorgopleidingen (HBO) en -organisaties verbonden of aan andere faculteiten (pedagogiek, psychologie).

$\mathrm{Er}$ is een gestage groei van personen die het onderwijsmateriaal in Blackboard bekijken of downloaden en gebruiken. Vanaf de lancering (1 mei 2003) tot 1 april 2004 zijn dat 43 personen die aan de medische faculteiten zijn verbonden en 20 personen die elders werkzaam zijn. Vanwege de introductie van een nieuwe versie van Blackboard zijn van 1 mei 2004 tot 1 januari 2005 geen gegevens geregistreerd en kon niet worden nagegaan hoeveel personen het onderwijsmateriaal hebben bekeken en/of gebruikt. Dat betekent een onderschatting van het aantal gebruikers. Van 1 januari 2005 tot 1 mei 2005 hebben
28 personen het seksespecifiek onderwijsmateriaal in Blackboard ingezien. Daarvan zijn 25 personen werkzaam bij een medische faculteit en 3 personen bij een andere instelling (tabel 2).

\section{Beoordeling Digitaal Kenniscentrum Seksespecifiek Medisch Onderwijs}

Alle zeventien respondenten vonden de website DKSMO duidelijk en overzichtelijk:

"Helder, verzorgd en de onderwerpen zijn goed te vinden." (AMC/\#1)

"De website heeft een zeer duidelijke structuur." (ErasmusMC/\#14)

Veertien van hen hebben het onderwijsmateriaal in het DKSMO ingezien. Drie respondenten hebben zich wel aangemeld, maar hebben geen gebruik gemaakt van het DKSMO. Redenen daarvan waren een te hoge drempel van de accountaanvraag en een verandering van functie. Ook het verkrijgen van papieren onderwijsmateriaal via de projectonderzoekers speelde een rol:

"Ik had de website niet nodig omdat ik al een aantal aanpassingen aan mijn blok had gedaan op basis van de aanbevelingen van jullie. Op basis daarvan heb ik casussen aangepast en een studente heeft ervoor gezorgd dat er een college wordt gegeven over multiculturaliteit in beleving van seksualiteit. Aan het blokboek

Tabel 2 Overzicht aantal personen dat actief gebruik maakt (bekijken en/of downloaden) van het seksespecifiek onderwijsmateriaal in Blackboard.

\begin{tabular}{lcccc}
\hline Gebruikers werkzaam bij: & $2003-2004$ & $2004-2005$ & 2005 & $2003-2005$ \\
\hline \multirow{2}{*}{ Medische faculteit } & 1 mei -1 april & 1 mei -1 januari & 1 januari -1 mei & 1 mei -1 mei \\
\cline { 2 - 5 } Overige instellingen & 43 & Geen registratie & 25 & 93 \\
Totaal & 20 & Geen registratie & 3 & 45 \\
\hline & 63 & Geen registratie & 28 & 138 \\
\hline
\end{tabular}


Sekse, Seksualiteit en Multiculturaliteit dat ik heb meegekregen, heb ik nog het meest gehad. Daar heb ik uit geleerd." $(\mathrm{AZM} / \# 7)$

Verschillende docenten hebben het onderwijsmateriaal in het DKSMO wel bekeken, maar gaven aan er geen gebruik van te hebben gemaakt. Eén respondent meldde dat er geen onderwijsmateriaal aanwezig was over het gewenste onderwerp. Andere respondenten hadden het onderwijsmateriaal alleen bekeken ter oriëntatie:

"De eerste keer dat ik bij het onderwijsmateriaal ging kijken was nog niet bekend welke rol ik in het onderwijs zou krijgen. Ik heb toen wel veel gestruind en ideeën opgedaan op welke manier aandacht voor sekse in het onderwijs kan komen." (VUmc/\#11)

Twee respondenten vonden dat het onderwijsmateriaal niet de gewenste vorm had, waardoor het niet bruikbaar was voor hun collegeopzet. Het onderwijsmateriaal werd door twee andere respondenten alleen onder de aandacht gebracht van docenten:

"Ik heb andere onderwijsmensen gewezen op de mogelijkheid om het onderwijsmateriaal uit Blackboard te gebruiken in het eigen onderwijs." (AMC/\#1)

Eén respondent gaf aan dat het oude curriculum niet meer veranderd mocht worden, maar er wel mee bezig te zijn. Deze respondent liet ook weten dat het DKSMO "wel helpt" om sekse in het onderwijsprogramma te integreren (UMC Groningen/\#16).

\section{Rol van het Digitaal Kenniscentrum Seksespecifiek Medisch Onderwijs bij de integratie van sekse in het medisch onderwijs}

Zes respondenten hebben onderwijsmateriaal uit het DKSMO in hun eigen onderwijs gebruikt en vonden het materiaal handzaam en gemakkelijk in te bouwen:

"De studieopdrachten sluiten naadloos aan.” (UMC Groningen/\#3)

Het onderwijsmateriaal uit het DKSMO fungeerde ook als voorbeeldfunctie om eigen materiaal seksespecifiek te maken.

Uit de antwoorden van respondenten blijkt dat het DKSMO op verschillende manieren een positieve bijdrage heeft geleverd aan onderwijsverandering, zoals de integratie van sekse in het medisch onderwijs:

"Jullie komen niet alleen iets vragen, namelijk aandacht voor sekse als determinant van gezondheid en ziekte, maar ook prachtig materiaal aanleveren." (UMC Groningen/\#3)

"Het is een mooi voorbeeld van hoe je kennis kunt delen met anderen.” (AMC/\#2)

"In het Digitaal Kenniscentrum wordt informatie bij elkaar gebracht, dat nergens anders zo te vinden is." (UMC Groningen/\#5)

De voorstellen tot verbetering van het onderwijsmateriaal omvatten vooral uitbreidingen: méér onderwijsmateriaal met toetsvragen en meer achtergrondinformatie per thema. Tot slot meldde een respondent:

"Ik heb meer aan de specifieke individuele feedback op ons onderwijsmateriaal gehad dan aan de website, misschien zou je die mogelijkheid op de website ook aan kunnen bieden." (AMC/\#4) 
Drie respondenten gaven aan dat de vertraging tussen de aanvraag en het verkrijgen van een account een belemmering vormde om het onderwijsmateriaal in het DKSMO te bekijken.

\section{Discussie}

Een belangrijke bevinding is dat veel mensen het DKSMO hebben geraadpleegd tijdens het project en dat een substantieel aantal van hen het onderwijsmateriaal heeft gebruikt. In het project leverden de projectonderzoekers ondersteuning op maat. Blokcoördinatoren en docenten kregen naar aanleiding van het screenen van het onderwijsmateriaal per faculteit aanbevelingen met relevant onderwijsmateriaal uit het DKSMO op schrift. Deze aanbevelingen zijn in individuele gesprekken en/of tijdens een coördinatorenoverleg besproken. Veel blokcoördinatoren en docenten voelden minder noodzaak om zelf nog in de database te zoeken, omdat ze al van onderwijsmateriaal waren voorzien. Uitspraken van verschillende respondenten maken duidelijk dat genderdeskundigen nodig blijven om specifiek te kijken naar het onderwijs van de eigen faculteit.

Degenen die werkelijk gebruik maken van het onderwijsmateriaal uit het DKSMO zijn tevreden, zo blijkt uit de antwoorden op de vraag of ze het seksespecifiek onderwijsmateriaal gemakkelijk kunnen inpassen in het onderwijs. Belangrijk voor hen is dat zij het seksespecifiek onderwijsmateriaal in het bestaande onderwijs probleemloos kunnen integreren of het als voorbeeld kunnen gebruiken om zelf materiaal mee te maken. Het centraliseren en toegankelijk maken van seksespecifiek onderwijsmateriaal ondersteunt naar de mening van docenten het aanpassen van onderwijs in de gewenste richting. Dit wordt eveneens bevestigd in studies in de Verenigde Staten, Canada en Australië.5-6 10-13
Redenen om onderwijsmateriaal uit het DKSMO niet te gebruiken, kwamen deels voort uit de vertraging in het systeem. Door de inrichting en het gebruik van Blackboard kan een gebruiker niet direct toegang krijgen tot het seksespecifiek onderwijsmateriaal. Dat is inderdaad teleurstellend. De voordelen van Blackboard, zoals de beveiliging van het onderwijsmateriaal, het zicht hebben op de aanmeldingen en het kostenaspect wogen voor ons echter zwaarder. De toegankelijkheid van het DKSMO is inmiddels verbeterd door de vertraging tussen de aanvraag en het toesturen van een account te korten van drie dagen naar één dag. Deels bleken de wisseling van functie en het nog niet bezig zijn met concreet onderwijs maken een verklaring voor het wel inzien, maar niet gebruiken van het digitale materiaal.

Uniek is dat het DKSMO digitaal onderwijsmateriaal aanbiedt dat aansluit bij diverse onderwijsvormen op de faculteiten. Het DKSMO wordt actief aangevuld en vier keer per jaar wordt door middel van een nieuwsbrief een overzicht aangeboden van nieuw onderwijsmateriaal op het gebied van geneeskunde en sekse. Deze nieuwsbrief wordt tevens als herinnering verstuurd.

Veel vergelijkingsmateriaal over de invloed van andere digitale kenniscentra op het terrein van het medisch onderwijs is er niet. In Nederland zijn wel meer initiatieven om onderwijsvernieuwing te bevorderen door onderwijsmateriaal digitaal beschikbaar te stellen, maar deze betreffen hoofdzakelijk 'leren met ICT'-projecten (Espelon, Centrum voor Digitaal Onderwijs, Digitale Universiteit, Onderwijsplein Anton). Ook de verschillende digitale kenniscentra rondom cultuur/etniciteit en gezondheid richten zich niet op onderwijsmateriaal, maar op onderzoek of voorlichting. Verschillende internationale projecten hebben wel een website ingericht met seksespecifiek on- 
derwijsmateriaal. Deze richten zich slechts op een beperkt aantal onderwerpen, zoals partnergeweld 14 en 'adolescent sexuality and reproductive health' (www.pedicases. org). Van deze projecten is ons geen evaluatie bekend.

\section{Conclusie}

Geconcludeerd kan worden dat het DKSMO een faciliterende rol speelt bij de integratie van de factor sekse in de medische curricula in Nederland. Het bevordert de implementatie, doordat seksespecifiek onderwijsmateriaal gemakkelijk aan bestaand onderwijs toegevoegd kan worden of als voorbeeld kan dienen voor nieuw onderwijs. Een database met seksespecifiek onderwijs op zichzelf blijkt echter onvoldoende. De ondersteuning op maat door genderdeskundigen is een noodzakelijke en aanvullende factor geweest om het proces van implementatie succesvol te maken. Ook geschreven materiaal wordt enthousiast ontvangen, zoals gebeurde bij het beschikbaar stellen van een casusbundel met vijftig patiëntencasus over sekse en diversiteit in het professioneel handelen in 2005. ${ }^{15}$

Dit onderzoek kent enkele beperkingen. Allereerst kan een kanttekening worden geplaatst bij de ongelijkmatige verdeling van het gebruik van het DKSMO over de medische faculteiten. Omdat diverse faculteiten in een ander stadium van curriculumontwikkeling verkeerden, was ook de fase van implementatie van het project 'Sekse in het medisch basiscurriculum' verschillend. Tevens kan sprake zijn van een selectiebias van de respondenten. $\mathrm{Na}$ juli 2004 is het aantal gebruikers van het DKSMO gegroeid en is de groep meer gelijkmatig over de faculteiten verdeeld. Nader onderzoek is nodig om uitvoeriger inzicht te krijgen op de manier waarop gebruikers het onderwijsmateriaal uit het DKSMO toepassen.
Het medisch onderwijs is voortdurend in ontwikkeling. Behalve de ontwikkeling van nieuwe basiscurricula, wordt in den lande steeds meer aandacht besteed aan de integratie van de factor sekse en cultuur als onderdeel van diversiteit. De ontwikkeling van het DKSMO laat zien, dat een kenniscentrum ondersteunend kan werken bij het beschikbaar stellen van reeds bestaand en nieuw onderwijsmateriaal. Het delen van kennis en samenwerking tussen de medische faculteiten ten behoeve van onderwijsverandering werkt stimulerend.

\section{Literatuur}

1. Zelek B, Phillips SP, Lefebvre Y. Gender sensitivity in medical curricula. Can Med Assoc J 1997; 156:1297-1300.

2. Verdonk P, Mans LJL, Lagro-Janssen ALM. Integrating gender in a basic medical curriculum. Med Educ 2005;39:1118-25.

3. Searle J. Introduction of a new curriculum in women's health in medical education: a framework for change. Women's Health Issues 1998;8(6):382-8.

4. Krasnoff MJ. Resources for teaching about women's health. Acad Med 2000;75(11):1087-94.

5. Beck Weiss L, Lee S, Levison SP. Barriers and solutions to implementing a new curriculum: lessons from the Women's Health Education Program at MCP Hahnemann School of Medicine. Journal of Women's Health \& Gender-Based Medicine 2000;9(2):153-60.

6. Patterson Neely KL, Stifel EN, Milberg LC. A systematic approach to faculty development in women's health: lessons from education, feminism, and conflict theory. Acad Med 2000;75:1095-1101.

7. Overduin M, Beernink M, editors. Een goede website opzetten (2)-Sitestrategie. In: Tekst \& Content 2002(7) [online magazine] [geciteerd op 13 maart 2006]. Beschikbaar op: http://www.hvds.nl.

8. Poels LG, Coetsier N. Eindrapportage invoering digitale leeromgeving Blackboard. Nijmegen: UMC St Radboud; 2004.

9. Sanden J van der, Lagro-Janssen T. Aandacht voor sekseverschillen ontbreekt in artsenopleiding. Med Contact 1999;54(36):1195-98.

10. Henrich JB. Women's health education initiatives: why have they stalled? Acad Med 2004;79(4):283-8.

11. Medical Women's International Association. Training manual for gender mainstreaming in health. MWIA; 2002.

12. Watson S. Gender in medical education. A collaborative curriculum project. Phase 1 Final 
Report. Toronto: Undergraduate Education Committee Gender Issues Committee/Council of Ontario Faculties of Medicine; 2003.

13. Nobelius AM, Wainer J. Gender and medicine: a conceptual guide for medical educators. Victoria: Monash University School of Rural Health; 2004.

14. Magrane D, Ephgrave K, Jacobs MB, Rusch R. Weaving women's health across clinical clerkships. Acad Med 2000;75:1066-70.

15. Mans LJL, Dijkstra AF, Lagro-Janssen ALM. Sekse en diversiteit in het professioneel handelen. 50 patiëntencasus voor het medisch onderwijs. Nijmegen: Vrouwenstudies Medische Wetenschappen UMC St Radboud; 2005.
De auteurs:

Drs. L.J.L. Mans is gezondheidswetenschapper en projectonderzoeker.

Drs. P. Verdonk is psycholoog en projectonderzoeker.

Mw. prof. dr. A.L.M. Lagro-Janssen is huisarts en projectleider.

Alle auteurs zijn verbonden aan de afdeling Vrouwenstudies Medische Wetenschappen van het UMC St Radboud te Nijmegen.

\section{Correspondentieadres:}

Mw. prof. dr. A.L.M. Lagro-Janssen, UMC St Radboud, Vrouwenstudies Medische Wetenschappen, HAG 117, Postbus 9101, 6500 HB Nijmegen, tel.: 024-3613110, fax: 024-3541862, A.Lagro-Janssen@hag.umcn.nl.

\section{Summary}

Introduction: The evaluation of the Nijmegen pilot project on Integration of gender into the medical undergraduate curriculum shows that offering gender specific educational materials with relevance to day-to-day medical practice facilitates successful implementation. A Digital Information Centre on Gender and Medical Education (DKSMO) in the form of a website was created to offer access to gender specific medical education materials to all faculties of medicine during the national project. The aim of this study is to examine users' opinions on DKSMO and whether it facilitates the integration of gender into medical education.

Method: A questionnaire was sent to twenty teachers and unit coordinators who were selected from one hundred persons who applied for an account to gain access to gender specific educational materials before July 2004. Seventeen respondents from six faculties of medicine completed the questionnaire.

Results: Of the seventeen respondents, six actually used DKMSO educational materials and found them easy to use and integrate into existing courses. Reasons for not using the educational materials were: availability of paper-based educational materials, DKMSO offered no educational materials that were relevant to the subject of interest, delay in the DKSMO system or no current active involvement in course development. The teachers used DKSMO educational materials as examples in creating their own assignments.

Conclusion: DKSMO facilitates the integration of gender into undergraduate medical education. The Internet facilitates access to gender specific educational materials. However, practical support from experts on gender specific education remains necessary. (Mans LJL, Verdonk P, Lagro-Janssen ALM. The role of the Digital Knowledge Centre on Gender Specific Medical Education in the integration of gender in medical education. Dutch Journal of Medical Education 2006;25(2):66-74.) 
Bijlage 1 Vragenlijst evaluatie Digitaal Kenniscentrum Seksespecifiek Medisch Onderwijs.
Algemeen
1. Functie:
2. Organisatie: ...
3. Geslacht: $\quad \ldots$
4. Geboortejaar: ...

\section{Toegankelijkheid website algemeen}

5. Wat is uw algemene indruk van de website?

6. Is de inhoud en de opbouw van de website duidelijk?

7. Krijgt u voldoende hulp via de postmaster? Zo nee, wat zou u verbeterd willen zien?

8. Heeft u nog een advies of idee ter verbetering van de publieke website www.vrouwenstudiesgeneeskunde.nl?

9. Vindt $\mathrm{u}$ de elektronische leeromgeving Blackboard, waar het eigenlijke onderwijsmateriaal staat gemakkelijk toegankelijk? Waarom wel/niet?

10. Was u reeds bekend met Blackboard?

11. Heeft u Blackboard reeds eerder ingezet voor uw eigen onderwijs?

\section{Inhoud van het seksespecifiek onderwijsmateriaal}

12. Vindt $u$ de informatie die $u$ in Blackboard kunt lezen rondom het seksespecifiek onderwijsmateriaal duidelijk? Zo nee, wat zou u daar anders aan willen zien?

13. Wat vindt $u$ van de opbouw van het onderwijsmateriaal?

14. Wat vindt $u$ van de alfabetische indeling op onderwerp/thema?

15. Heeft $u$ het seksespecifiek onderwijsmateriaal gebruikt? Ja/nee? (indien ja, ga door naar vraag 19)

16. Zo nee, kunt $u$ aangeven wat de redenen daarvan waren?

17. Zijn deze redenen te ondervangen, zodat u wel het seksespecifiek onderwijsmateriaal zou gebruiken? (ga door naar vraag 23)

18. Zo ja, welk seksespecifiek onderwijsmateriaal heeft u gebruikt?

19. In welk onderwijsblok/voor welke onderwijsvorm heeft $u$ het seksespecifiek onderwijsmateriaal gebruikt?

20. Op welke manier heeft $u$ het seksespecifiek onderwijsmateriaal gebruikt?

21. Heeft $u$ het seksespecifiek onderwijsmateriaal gemakkelijk kunnen inpassen in uw onderwijs? Waarom wel/niet?

22. Voldoet dit Kenniscentrum aan uw behoeften bij het aanbrengen van wijzigingen in uw onderwijsprogramma om sekse te integreren? Zo ja, kunt u daarvan een voorbeeld geven? Zo nee, waarom niet?

23. Zou u het Digitaal Kenniscentrum Seksespecifiek Medisch Onderwijs aan anderen aanbevelen om te gebruiken?

24. Heeft u nog een adviezen ter verbetering van het onderwijsmateriaal in Blackboard?

\section{Aanvullende vragen rondom Nieuwsbrief}

25. Bent $u$ bekend met de nieuwsbrief van het Digitaal Kenniscentrum Seksespecifiek Medisch Onderwijs? (Twee keer verstuurd, in januari/februari 2004 en juni 2004)

26. Wat vindt $u$ van de inhoud van deze nieuwsbrief?

27. Heeft deze nieuwsbrief er voor gezorgd dat u weer gekeken heeft naar onderwijsmateriaal in het Digitaal Kenniscentrum Seksespecifiek Medisch Onderwijs? Waarom wel/niet? 